\title{
A hybrid approach based on the BWM-VIKOR and GRA for ranking facility location in construction site layout for Mehr project in Tehran
}

\author{
Abdolrasoul Parhizgarsharif ${ }^{\mathrm{a}}$, Alireza Lork $^{\mathrm{b}^{*}}$ and Abdolrasoul Telvaric
}

${ }^{a}$ Department of civil Engineering, Roudehen Branch, Islamic Azad University, Roudehen, Iran

${ }^{b}$ Department of civil Engineering, Safadasht Branch, Islamic azad University, Tehran, Iran

${ }^{c}$ Department of civil Engineering, Ahvaz Branch, Islamic Azad University, Ahvaz, Iran

\section{H R O N I C L E}

Article history:

Received February 2, 2019

Received in revised format:

March 8, 2019

Accepted March 10, 2019

Available online

March 10, 2019

Keywords:

Site Facilities

Safety Criteria

Best-Worst Method (BWM)

VIKOR Method

Gray Relational Analysis (GRA)

Mehr Construction Project of

Tehran

\begin{abstract}
A B S T R A C T
This study presents a new hybrid framework based on the multi-criteria decision making in order to rank the potential site layout locations by consideration of the cost and safety criteria in the Mehr Construction Project in Tehran, Iran. To this end, all of the criteria in selecting suitable potential locations are extracted from the research literature and the most effective ones, which are matched with existing conditions in Tehran are considered based on the opinion of experts,. Then, the proper locations for site layout are determined as the potential alternatives and ranked by experts based on the structure. According to the data collected from the questionnaires, the weights of the selected criteria are calculated using Best Worst Method (BWM) and the final ranking of the locations is performed using two Gray Relational Analysis and VIKOR methods. The computational results indicate that both VIKOR and GRA methods yield the same ranking. However, a method with higher reliability should be used to select the best potential location of construction site layout. Therefore, the sensitivity analysis of final outputs on the parameters existing in VIKOR and GRA methods is used in order to rank the alternatives and select the best approach. According to the computational results, the GRA method provides higher robustness compared with the VIKOR method. Accordingly, the ranking obtained from the GRA method is employed as the final solution in implementing the case study.
\end{abstract}

\section{Introduction}

Heavy costs are spent on safety and suitable layout of facilities in some applications such as civil projects and non-civil projects performed by government and private or public sectors respectively; hence, the most important goal of such problems is to minimize system costs and maximizing safety level (Kumar \& Cheng, 2015; Said \& El-Rayes, 2013). Many studies examined this problem only by consideration of minimizing costs while managers tend to optimize more objectives like safety level maximization in the real world. On the other hand, changing a facility layout after implementation of a project is difficult or infeasible; accordingly, it is essential to consider all of the criteria affecting the final decision-making (Yahya \& Saka, 2014). Another important point for the implementation of all industrial and construction projects is the safety level and factors affecting it. This is a vital issue because endangered safety of workers, managers and equipment may lead to costly postponements and

* Corresponding author. Tel. : +98-901-816-7027

E-mail address: 1 orkdr@gmail.com (A. Lork) 
heavy private or public fines when workers' safety is at risk (Kaveh et al., 2018). Therefore, a suitable model should be proposed for proper facilities layout in construction projects efficiently by considering all of the effective factors.

In this research, a hybrid method based on the BWM, VIKOR and GRA is presented to prioritize the potential locations for construction site layout. This subject has been less considered by the researchers. Jozi et al. (2015) employed the hybrid analytical hierarchy (AHP) process (Saaty, 2003) with data envelopment analysis (DEA) (Banker et al., 1984) in order to rank layout design patterns. They applied AHP method to determine functional values of qualitative criteria in order to use them in the DEA model. Durmusoglu (2018) used a similar approach to prioritize layout design patterns with the different method in which, two fuzzy variables of information flow and environmental condition were used to determine the relationships between activities and closeness ratings based on the fuzzy decision system. Ardeshir et al. (2014) used the searching GA approach and the ELECTRE multi-criteria decision-making method (Jain \& Ajmera, 2019) in order to rank the patterns. In this research, Paretooptimal solution was determined using boundary multi-objective genetic algorithms then the optimal solution was selected using the ELECTRE method. Nguyen et al. (2016) employed the TOPSIS approach (Biswas \& Saha, 2019) in order to prioritize site layout designs then compared the obtained results to the results of TOPSIS. The proposed approach dramatically depends on the subjective judgments of the designers.

Marzouk and Al Daour (2018) presented a decision-making system, which consists of input, design, evaluation, selection and output steps in order to solve the construction site layout planning multiobjective dynamic problem. Various objectives, scheduling plan and sites conditions were determined at the input step. At the design step, two mathematical optimization models of Max-Min ant system (MMAS) and the corrected algorithm based on the Pareto Ant Colony Optimization were presented to solve single-objective and multi-objective optimization problems, respectively. Ultimately, The Fuzzy TOPSIS (Aikhuele, 2019) method was used at evaluation and selection steps in order to evaluate and select the best layout design among other generated designs at the design step. Mytilinou et al. (2018) carried out a study in which, construction site criteria were ranked using quality management, cost, and safety approach in construction projects using TOPSIS method. This study was conducted to be beneficial for project managers' success. Analyzing sub-criteria based on the above-mentioned method, projection type, safety, project programming, work time and building dimensions were selected as prior cases, respectively. Abune'Meh (2017) carried out a study where the criteria affecting the evaluation of layout designs were identified at first step and a hybrid fuzzy multi-criteria decision-making method was presented to select the optimum layout design. In this method, Fuzzy Group AHP, Shannon entropy (Vatansever \& Akgül, 2018), and TOPSIS were utilized to determine the functional values of layout designs by consideration of qualitative criteria, to calculate criteria's weights and to rank final layout designs, respectively. Moreover, qualitative and quantitative criteria were taken into account simultaneously so that the function of layout designs was considered for qualitative criteria within a fuzzy method. In addition, the optimal design was selected proportionally without considering the relative importance between criteria based on the opinions of experts.

Esfahani and Nik (2016) carried out a study in order to address the layout of some facilities like Tower Crane in construction site and effective factors of these facilities in construction site safety and proposed an appropriate solution to increase safety within design step. Ning et al. (2016) conducted a study where AHP approach was used to determine functional values of qualitative criteria. They employed a commercial software to create layout patterns and functional quantitative values and finally used a non-linear weighted optimization model for order of layout design patterns in presence of two groups of criteria considering the order of criteria based on the designers' ideas. This study implemented the obtained model in a real case study in order to show the model applicability then presented the results. Table 1 reports a classification of multi-criteria decision-making methods that have been used in previous studies. 
Table 1

Different types of decision-making methods for energy sites selection

\begin{tabular}{|c|c|c|c|c|c|c|c|c|c|}
\hline \multirow{2}{*}{ Ref. } & \multicolumn{9}{|c|}{ MCDM Methods } \\
\hline & AHP & ANP & ELECTRE & DEMATEL & TOPSIS & OWA & GRA & VIKOR & BWM \\
\hline Önüt et al., 2010) & $\sqrt{ }$ & & & & & & & & \\
\hline Ataei \& Branch, 2013 & $\sqrt{ }$ & & & & & & & & \\
\hline Zavadskas et al., 2013 & $\sqrt{ }$ & & & & $\sqrt{ }$ & & & & \\
\hline Stanujkić et al., 2013 & & & $\sqrt{ }$ & & & & & & \\
\hline Jato-Espino et al., 2014 & & & $\sqrt{ }$ & & & & & & \\
\hline Ardeshir et al., 2014 & $\sqrt{ }$ & & & & & & & & \\
\hline Ardeshir et al., 2014 & & $\sqrt{ }$ & & $\sqrt{ }$ & & & & & \\
\hline Jozi et al., 2015 & $\sqrt{ }$ & & & & & & & & \\
\hline Nguyen et al., 2016 & $\sqrt{ }$ & & & & & & & $\sqrt{ }$ & \\
\hline Abune'Meh, 2017 & $\sqrt{ }$ & & & & & & & & \\
\hline Arashpour et al., 2018 & & & & & & $\sqrt{ }$ & & & \\
\hline Durmusoglu, 2018 & & $\sqrt{ }$ & & $\sqrt{ }$ & & & & & \\
\hline Al Hawarneh et al., 2019 & & $\sqrt{ }$ & & & & & & $\sqrt{ }$ & \\
\hline The proposed Study & & & & & & & $\sqrt{ }$ & $\sqrt{ }$ & $\sqrt{ }$ \\
\hline
\end{tabular}

According to Table 1, most of the studies have utilized AHP method. In fact, AHP is one of the widely used decision-making methods in this area (Kumar et al, 2017). Some of decision-making methods like TOPSIS and VIKOR have been also employed with AHP in a hybrid method. However, the interesting point is that the new decision-making methods such as BWM and GRA have not been considered by the researchers in this field while BWM is a more powerful approach used to determine weight of criteria compared to the other decision-making methods (Rezaei, 2016). This method can find the weight of criteria precisely by using a linear optimization model. Except the questionnaires that have been filled out with the experts and there is not any user interference in determining weight of these criteria (Rezaei, 2015). Hence, the obtained weights have an acceptable reliability. Furthermore, GRA method is highly robust in final ranking of alternatives based on the criteria (Zhang et al., 2011). Therefore, the present study uses a hybrid approach based on BWM, GRA and VIKOR methods in order to expand the application of these methods in finding suitable locations for construction site layout. This paper has been organized as follows: section 2 explains the research problem and introduces the taken alternatives and criteria. Section 3 describes the applied multi-criteria decisionmaking methods. Section 4 presents the computational results. Finally, section 5 presents a summary of research results.

\section{Definitions and Concepts of BWM, VIKOR and GRA Technics}

This section introduces the definitions related to BWM and VIKOR and GRA technics as well as the Monte Carlo Simulation Method. The hybrid model of MCDM is suggested based on the basic concept.

\subsection{The Best Wordt-Method}

BWM is a robust method proposed to solve MCDM problems and is used to calculate the weights of alternatives and criteria (Rezaei, 2015, 2016). This method removes weaknesses such as incompatibility of pairwise comparison-based methods (e.g AHP and ANP). In recent years, BWM has been employed by many researchers to determine weights and rank alternatives in different fields. In general, structure of BWM method steps is as follows:

Step 1: creation of decision criterion system: decision criterion system comprises a set of identified criteria by reviewing literature and experts' opinions as a set of $\left\{\mathrm{c}_{1}, \mathrm{c}_{2}, \ldots, \mathrm{c}_{\mathrm{n}}\right\}$. Values of decision criteria reflect function of different alternatives.

Step 2: determining the best and the worst criteria among the main criteria and sub-criteria; according to decision criterion system, the best and worst criteria should be identified by decision makers. The best criterion is indicated by $\mathrm{C}_{\mathrm{B}}$ and the worst criterion is shown by $\mathrm{W}_{\mathrm{B}}$. 
Step 3: Reference comparisons for the best criterion: This step determines the priority of the best criterion compared with other criteria using values between 1 and 9 based on the verbal comparison scale, which is presented in Table 5. Results are indicated in a vector:

$$
A_{B}=\left(a_{B 1}, a_{B 2}, \ldots, a_{B n}\right)
$$

where, $a_{B j}$ is the priority related to the best-selected criterion of $B$ compared to each criterion of $j$. So, $a_{B B}=1$.

Step 4: Reference comparisons for the worst criterion: priority of all of the criteria related to worst selected criterion is calculated using values 1-9 in the same way. Results of this vector shown as follows:

$$
A_{w}=\left(a_{1 W}, a_{2 W}, \ldots, a_{n W}\right)^{T},
$$

where, $a_{j W}$ indicates the priority of each criterion $j$ relative to the worst selected criterion of $W$. obviously, $a_{W W}=1$

Step 5: Determine the optimal weights $\left(W_{1}^{*}, W_{2}^{*}, \ldots, W_{n}^{*}\right)$ : to achieve the optimal weights of the criteria at this step, the highest absolute difference $\left\{\left|w_{B}-a_{B j} w_{j}\right|,\left|w_{j}-a_{j W w_{W}}\right|\right\}$ should be minimized for all of js values. This is formulated as following optimization problem:

$$
\begin{aligned}
& \underset{j}{\min \max _{j}}\left\{\left|w_{B}-a_{B j} w_{j}\right|,\left|w_{j}-a_{j W} w_{W}\right|\right\} \\
& \text { subject to } \\
& \sum_{j} w_{j}=1 \\
& w_{j} \geq 0, \text { for all } j
\end{aligned}
$$

Problem (3) can be modified to the following model:

$$
\begin{aligned}
& \min \xi^{L} \\
& \text { subject to } \\
& \left|w_{B}-a_{B j} w_{j}\right| \leq \xi^{L}, \text { for all } j \\
& \left|w_{j}-a_{j W} w_{W}\right| \leq \xi^{L}, \text { for all } j \\
& \sum_{j} w_{j}=1 \\
& w_{j} \geq 0, \text { for all } j
\end{aligned}
$$

Model (4) is linear with exclusive solution. Hence, optimal weights $\left(w_{1}^{*}, w_{2}^{*}, \ldots, w_{n}^{*}\right)$ and optimal value of $\xi^{L *}$ are obtained with solving this model. Values near to zero $\left(\xi^{L *}\right)$ in this model indicate high compatibility level (Rezaei, 2016).

\subsection{Grey Relational Analysis Technique}

Grey Relational Analysis (GRA) was developed by Deng (1982). Grey system theory is an algorithm that analyzes the indefinite relations between members of a system. This algorithm can be used in multicriteria decision-making problems. This approach is able to identify both qualitative and quantitative relationships between sophisticated factors within a system. The approach can examine the relationship between two alternatives by measuring the distance between them. It is assumed that the multi-criteria decision-making problem consists of $m$ alternatives $\mathrm{A}_{1}, \mathrm{~A}_{2}, \ldots, \mathrm{A}_{\mathrm{m}}$ and $n$ criteria $\mathrm{C}_{1}, \mathrm{C}_{2}, \ldots, \mathrm{C}_{\mathrm{n}}$ so that each alternative is evaluated based on the $n$ criteria and all of the measured values are assigned to the alternatives and shown based on the decision matrix $Y\left(=\left(y_{i j}\right)_{m \times n}\right)$. GRA steps are as follows: 
Step 1: Calculate the normal decision matrix and normalized value $x_{i j}$ using Eq. (5) and Eq. (6).

$$
\begin{gathered}
x_{i j}=\frac{y_{i j}-\operatorname{Min}\left\{y_{i j}, i=1,2, \ldots, m\right\}}{\operatorname{Max}\left\{y_{i j}, i=1,2, \ldots, m\right\}-\operatorname{Min}\left\{y_{i j}, i=1,2, \ldots, m\right\}} \quad i=1,2, \ldots, m ; j=1,2, \ldots, n \text {; for } j \in I \\
x_{i j}=\frac{\operatorname{Max}\left\{y_{i j}, i=1,2, \ldots, m\right\}-y_{i j}}{\operatorname{Max}\left\{y_{i j}, i=1,2, \ldots, m\right\}-\operatorname{Min}\left\{y_{i j}, i=1,2, \ldots, m\right\}} \quad i=1,2, \ldots, m ; j=1,2, \ldots, n ; \text { for } j \in J
\end{gathered}
$$

where, $i$ represents the sequence of benefit criteria and $\mathrm{J}$ is the sequence of costs.

Step 2: Determine the reference sequence $x_{0}$ using the Eq. (7).

$$
x_{0}=\left\{x_{01}, x_{02}, \ldots, x_{0 n}\right\}
$$

where, $x_{0 j}=\max _{j} x_{i j}$ and $j=1,2, \ldots, n$.

Step 3: calculate the gray relational degree using the Eq. (8).

$$
\gamma\left(x_{0 j}, x_{i j}\right)=\frac{\min _{i} \min _{j} \Delta_{i j}+\xi \max _{i} \max _{j} \Delta_{i j}}{\Delta_{i j}+\xi \max _{i} \max _{j} \Delta_{i j}}
$$

where, $\Delta_{i j}=\left|x_{0 j}-x_{i j}\right|, i=1,2, \ldots, m, j=1,2, \ldots, n$, and $\xi$ is the fix coefficient $\xi=[0,1]$, which equals 0.5 in this research.

Step 4: The gray relational rate between $x_{0}$ and $x_{i}$ is calculated using Eq. (9) by calculating all of gray relational degrees.

$$
\Gamma\left(x_{0}, x_{i}\right)=\sum_{j=1}^{n} w_{j} \gamma\left(x_{0 j}, x_{i j}\right), \quad \sum_{j=1}^{n} w_{j}=1
$$

where, $w_{j}$ indicates the weight of criteria and $i=1,2, \ldots, m, j=1,2, \ldots, n$.

Step 5: ranking the alternatives based on the gray relational value in a way that the greater value of $\Gamma\left(x_{0}, x_{i}\right)$ shows the optimality of alternative $A_{i}$.

\subsection{VIKOR Technique}

VIKOR technique is a customized ordering method, which is mostly used in presence of different conflicting criteria (Opricovic, 1998). This is a compromise solution based on the closeness to the ideal solution and an agreement established by mutual concessions. This method has been widely used by researchers to rank the alternatives. VIKOR Method has the following steps (Gupta, 2018):

Step 1: Calculate the pairwise matrix for each alternative so that each criterion is evaluated using the verbal scale, which is presented in Table 4.

Step 2: Calculate the average decision matrix using Eq. (10).

$$
f_{i j}=\frac{1}{k} \sum_{t=1}^{k} x_{i j}^{t} \quad i=1,2, \ldots, m ; j=1,2, \ldots, n
$$

where, $x_{i j}^{t}$ is the value of alternative $i$ relative to the criterion $j$ given by the expert $t$.

Step 3: Calculate the best $f_{j}^{*}$ and the worst $f_{j}^{-}$of all criteria using Eq. (11) and Eq. (12). 


$$
\begin{array}{ll}
f_{j}^{*}=\max _{i j}, & i=1,2, \ldots, m ; j=1,2, \ldots, n \\
f_{j}^{-}=\operatorname{minf}_{i j}, & i=1,2, \ldots, m ; j=1,2, \ldots, n
\end{array}
$$

where, $f_{j}^{*}$ represents the positive ideal solution and $f_{j}^{-}$represents the negative ideal solution for criterion $j$.

Step 4: Compute the values $S_{i}$ and $R_{i} i=1,2, \ldots, m$ by the Eq. (13) and Eq. (14).

$$
\begin{aligned}
& S_{i}=\sum_{j=1}^{n} w_{j} \frac{\left(f_{j}^{*}-f_{i j}\right)}{\left(f_{j}^{*}-f_{j}^{-}\right)}, \\
& R_{i}=\max \left[w_{j} \frac{\left(f_{j}^{*}-f_{i j}\right)}{\left(f_{j}^{*}-f_{j}^{-}\right)}\right],
\end{aligned}
$$

where, $S_{i}$ represent the distance between the positive ideal solution and alternative $i ; R_{i}$ represents the distance between the negative ideal solution and alternative $i, w_{j}$ indicates the weights of factors obtained from fuzzy BWM analysis.

Step 5: compute the $Q_{i}$ value by the Eq. (15).

$$
Q_{i}=v\left[\frac{S_{i}-S^{*}}{S^{-}-S^{*}}\right]+(1-v)\left[\frac{R_{i}-R^{*}}{R^{-}-R^{*}}\right]
$$

where, $S^{-}=\max _{i} S_{i}, S^{*}=\min _{i} S_{i}$ and $R^{-}=\max _{i} R_{i}, R^{*}=\min _{i} R_{i}$ and parameter $v$ is introduced as a weight for the strategy of "the majority of criteria", which equals 0.5 in this research.

Step 6: Rank the alternatives using $Q_{i}$ values.

Step 7: The alternatives are ranked based on the minimum $Q_{i}$ if the following two conditions are satisfied:

$\mathrm{C}_{1}$. "Acceptable Advantage": the alternative $\mathrm{A}^{1}$ is chosen if $Q\left(A^{2}\right)-Q\left(A^{1}\right) \geq 1 / m-1$ where, $A^{2}$ is the alternative with the second position and $m$ represents the total alternatives.

$\mathrm{C}_{2}$. "Acceptable stability in decision making": The alternative $A^{1}$ must also be the best ranked by $S_{i}$ and or $R_{i}$ values.

Step 8: The alternative with the minimum value in $Q_{i}$ should be ranked at the first position.

\section{Computational Results}

This section examines the results obtained from the case study, which in the Mehra Housing construction project in Tehran, Iran using the proposal method. Some information were randomly generated based on the problem structure due to inaccessibility to all data of the project. In this project, 40 potential locations have been selected to establish 20 facilities by the experts.

\begin{tabular}{lll}
\hline 1- Metal and concrete material storage 1 & 2- Self-service and Residence & 3- Metal and concrete material storage 2 \\
4- Engineering offices and laboratory & 5- Metal and concrete material storage 3 & 6- Joist, block and slab workshop 1 \\
7- Material indoor storage 1 & 8- Joist, block and slab workshop 2 & 9- Material indoor storage 2 \\
10- Joist, block and slab workshop 3 & 11-Material indoor storage 3 & 12- Forging and carpentry workshop 1 \\
13- Material indoor storage 4 & 14- Forging and carpentry workshop 2 & 15- Material indoor storage 5 \\
16- Parking for passenger vehicles & 17- Electrical and mechanical & 18- Parking for heavy and construction \\
& equipment indoor storage 1 & vehicles \\
19- Electrical and mechanical equipment indoor storage 2 & 20- Repair shop \\
\hline
\end{tabular}


Fig. 1 demonstrates the initial site of the studied construction workshop.

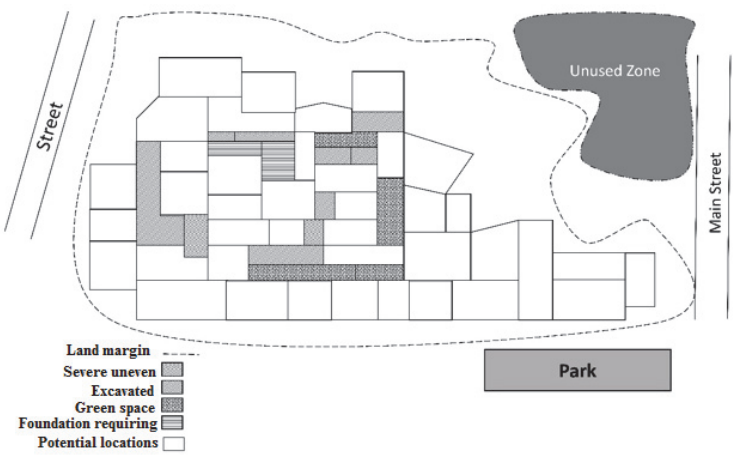

Fig. 1. The initial site of the studied workshop

Methodology steps to achieve the results have been presented in following sections.

3.1 Determining the weights of the criteria affecting the increasing safety level and ranking the potential locations for site layout

Data analysis is a multistep process in which, the data that have been collected by using the data collecting tools in the statistical sample (society) are summarized, coded, classified and processed in order to provide the field for analyses and relationships between the data to achieve the research goals. In this process, the data are refined conceptually and empirically.

\subsection{Validation of safety criteria}

Lawshe's Validation was used in this section by distributing and collecting the questionnaire (1) in order to determine safety criteria affecting the site layout. In this case, 30 experts were interviewed to determine validity of the identified criteria, which the results are reported in Table 1.

\section{Table 1}

Results of validating the safety criteria affecting site layout

\begin{tabular}{llllllll}
\hline Criterion & N & ne & CVR & Criterion & N & ne & CVR \\
\hline Visual beauty & 30 & 19 & 0.27 & The relationship between labor and equipment & 30 & 27 & 0.80 \\
Safety flexibility of equipment & 30 & 28 & 0.87 & Automation level of equipment & 30 & 18 & 0.20 \\
Light shortage & 30 & 26 & 0.73 & type of products & 30 & 19 & 0.27 \\
Respiratory risks & 30 & 27 & 0.80 & Product features & 30 & 19 & 0.27 \\
Association with the other parts & 30 & 19 & 0.27 & Suitable final plan & 30 & 28 & 0.87 \\
Possible further development & 30 & 18 & 0.20 & Temperature changes & 30 & 14 & -0.07 \\
Safe feeding equipment & 30 & 15 & 0.00 & Noise disturbance & 30 & 18 & 0.20 \\
Access to standard equipment & 30 & 27 & 0.80 & Safe access to the raw materials & 30 & 26 & 0.73 \\
Protective equipment for labor & 30 & 25 & 0.67 & Wastewater and waste disposal & 30 & 18 & 0.20 \\
Materials safety information and & 30 & 28 & 0.87 & Fire and explosion & 30 & 19 & 0.27 \\
guidelines & & & & & & & \\
\hline
\end{tabular}

As there are 30 evaluators, the minimum CVR equals to 0.33 according to the table 1 . Therefore, the finalized safety criteria affecting the site layout are indicated in Table 2:

Table 2

Final criteria for site layout

\begin{tabular}{|c|c|c|c|}
\hline Final criteria for layout evaluation & ID & Final criteria for layout evaluation & ID \\
\hline Safety flexibility of equipment & $\mathrm{C}_{1}$ & Materials safety information and guidelines & $\mathrm{C}_{6}$ \\
\hline Light shortage & $\mathrm{C}_{2}$ & The relationship between labor and equipment & $\mathrm{C}_{7}$ \\
\hline Respiratory risks & $\mathrm{C}_{3}$ & Suitable final plan & $\mathrm{C}_{8}$ \\
\hline Access to standard equipment & $\mathrm{C}_{4}$ & Safe access to the raw materials & $\mathrm{C}_{9}$ \\
\hline Protective equipment for labor & $\mathrm{C}_{5}$ & & \\
\hline
\end{tabular}




\subsection{Weights of safety criteria}

This section presents the results of the most important (best) and unimportant (worst) criteria using the BWM questionnaire. To valuate criteria, the opinions of an expert committee in the area of HS were used. The best and worst criteria identified by each respondent were the most important and unimportant criteria affecting site layout, respectively based on the experts' opinions. The best and worst criteria, which are identified by experts, can be seen in Table 3 .

Table 3

The best and worst identified criterion by the experts

\begin{tabular}{ccc}
\hline The most unimportant criterion & The most important criterion & Relevant criterion \\
\hline- & 1,5 & $\mathrm{C}_{1}$ \\
- & $3,7,8$ & $\mathrm{C}_{2}$ \\
$1,4,5$ & - & $\mathrm{C}_{3}$ \\
- & 4,2 & $\mathrm{C}_{4}$ \\
- & - & $\mathrm{C}_{5}$ \\
- & 6 & $\mathrm{C}_{6}$ \\
2,7 & - & $\mathrm{C}_{7}$ \\
3,8 & - & $\mathrm{C}_{8}$ \\
6 & - & $\mathrm{C}_{9}$ \\
\hline
\end{tabular}

This part of study determines the preferences of the the best criterion among all of the criteria. This information is obtained from distributing and collecting the BWM questionnaire so that the respondents are asked to identify the preference of the best criterion relative to other criteria. Therefore, the bestother criteria vectors are indicated in Table 4.

Table 4

The best-other criteria vectors

\begin{tabular}{rcccccccccc}
\hline Experts & The best criterion & $C_{1}$ & $C_{2}$ & $C_{3}$ & $C_{4}$ & $C_{5}$ & $C_{6}$ & $C_{7}$ & $C_{8}$ & $C_{9}$ \\
\hline Expert 1 & $\mathrm{C}_{1}$ & 1 & 3 & 9 & 2 & 4 & 2 & 3 & 2 & 4 \\
Expert 2 & $\mathrm{C}_{4}$ & 4 & 2 & 3 & 1 & 2 & 2 & 8 & 3 & 4 \\
Expert 3 & $\mathrm{C}_{2}$ & 2 & 1 & 4 & 2 & 2 & 3 & 2 & 9 & 4 \\
Expert 4 & $\mathrm{C}_{4}$ & 2 & 3 & 8 & 1 & 4 & 2 & 2 & 3 & 5 \\
Expert 5 & $\mathrm{C}_{1}$ & 1 & 2 & 9 & 3 & 2 & 2 & 3 & 4 & 2 \\
Expert 6 & $\mathrm{C}_{6}$ & 2 & 3 & 2 & 4 & 2 & 1 & 3 & 3 & 9 \\
Expert 7 & $\mathrm{C}_{2}$ & 3 & 1 & 2 & 2 & 3 & 2 & 9 & 2 & 5 \\
Expert 8 & $\mathrm{C}_{2}$ & 3 & 1 & 3 & 2 & 2 & 5 & 2 & 8 & 2 \\
\hline
\end{tabular}

Preferences of other criteria relative to the worst criterion are determined in a same way. This information is obtained from distributing and collecting the BWM questionnaire so that the respondents are asked to identify the preference of the worst criterion relative to other criteria. Therefore, the worstother criteria vectors are indicated in Table 5.

Table 5

The worst-other criteria vectors

\begin{tabular}{|c|c|c|c|c|c|c|c|c|}
\hline Experts & Expert 1 & Expert 2 & Expert 3 & Expert 4 & Expert 5 & Expert 6 & Expert 7 & Expert 8 \\
\hline The worst criterion & $C_{3}$ & $C_{7}$ & $C_{8}$ & $C_{3}$ & $C_{3}$ & $C_{9}$ & $C_{7}$ & $C_{8}$ \\
\hline \multicolumn{9}{|l|}{ Criterion } \\
\hline $\mathrm{C}_{1}$ & 9 & 2 & 2 & 2 & 9 & 2 & 2 & 2 \\
\hline $\mathrm{C}_{2}$ & 2 & 3 & 9 & 4 & 2 & 2 & 9 & 8 \\
\hline $\mathrm{C}_{3}$ & 1 & 2 & 3 & 1 & 1 & 3 & 2 & 2 \\
\hline$C_{4}$ & 2 & 8 & 5 & 8 & 5 & 4 & 3 & 3 \\
\hline$C_{4}$ & 3 & 3 & 2 & 2 & 4 & 5 & 5 & 5 \\
\hline $\mathrm{C}_{6}$ & 4 & 2 & 2 & 5 & 3 & 9 & 2 & 3 \\
\hline $\mathrm{C}_{7}$ & 3 & 1 & 2 & 3 & 2 & 3 & 1 & 3 \\
\hline $\mathrm{C}_{8}$ & 2 & 4 & 1 & 2 & 3 & 2 & 4 & 1 \\
\hline $\mathrm{C}_{9}$ & 2 & 2 & 3 & 2 & 3 & 1 & 2 & 2 \\
\hline
\end{tabular}


Ultimately, the best-worst method is employed to determine the results of consistency coefficient of pairwise comparisons as well as the weights of the criteria affecting site layout. The weights of safety criteria are calculated by solving the linear WBM technique among eight experts and using GAMS24.3 Software and BARON solver. These weights are the average weights for each criterion, which are demonstrated in a unit weigh vector in Table 6.

\section{Table 6}

Weights of safety criteria for site layout

\begin{tabular}{|c|c|c|c|c|c|c|c|c|c|}
\hline \multirow{2}{*}{ Criterion } & \multicolumn{8}{|c|}{ Respondent (Experts) } & \multirow{2}{*}{$\begin{array}{c}\text { Final } \\
\text { weights }\end{array}$} \\
\hline & $\mathbf{R}(1)$ & $\mathbf{R}(2)$ & $\mathbf{R}(3)$ & $\mathbf{R}(4)$ & $\mathbf{R}(\mathbf{5})$ & $\mathbf{R}(6)$ & $\mathbf{R}(7)$ & $\mathbf{R}(8)$ & \\
\hline Safety flexibility of equipment & 0.256 & 0.072 & 0.103 & 0.106 & 0.253 & 0.100 & 0.097 & 0.091 & 0.135 \\
\hline Light shortage & 0.099 & 0.139 & 0.256 & 0.097 & 0.104 & 0.095 & 0.246 & 0.236 & 0.159 \\
\hline Respiratory risks & 0.033 & 0.096 & 0.077 & 0.034 & 0.028 & 0.129 & 0.101 & 0.091 & 0.074 \\
\hline Access to standard equipment & 0.107 & 0.249 & 0.103 & 0.251 & 0.099 & 0.071 & 0.129 & 0.130 & 0.142 \\
\hline Protective equipment for labor & 0.074 & 0.139 & 0.103 & 0.072 & 0.149 & 0.143 & 0.095 & 0.0137 & 0.114 \\
\hline $\begin{array}{l}\text { Materials safety information and } \\
\text { guidelines }\end{array}$ & 0.149 & 0.105 & 0.103 & 0.145 & 0.133 & 0.243 & 0.101 & 0.055 & 0.129 \\
\hline $\begin{array}{l}\text { The relationship between labor } \\
\text { and equipment }\end{array}$ & 0.099 & 0.033 & 0.154 & 0.140 & 0.099 & 0.095 & 0.028 & 0.130 & 0.097 \\
\hline Suitable final plan & 0.107 & 0.095 & 0.026 & 0.097 & 0.075 & 0.095 & 0.145 & 0.031 & 0.084 \\
\hline Safe access to the raw materials & 0.076 & 0.072 & 0.077 & 0.058 & 0.060 & 0.029 & 0.058 & 0.099 & 0.066 \\
\hline$\xi^{\mathrm{L}^{*}}$ & 0.041 & 0.038 & 0.051 & 0.039 & 0.046 & 0.043 & 0.044 & 0.038 & 0.043 \\
\hline
\end{tabular}

Here $\xi^{L^{*}}$ represents consistency of comparisons. According to the Table 6, comparisons are highly compatible due to their proximity to zero. It is concluded from the pairwise comparisons between the criteria that the obtained weights for criteria of light shortage, access to standard equipment and safety flexibility of equipment had the highest values respectively relative to the other criteria. Table 6 shows that the final value of CR is lower than 0.1 indicating the proper criteria selection to achieve the result. In fact, it can be stated based on the opinions of experts that the introduced criteria had an appropriate consistency and could affect the final responses.

\subsection{Evaluation of potential locations}

At this step, 40 potential locations are evaluated for site layout. To facilitate this process, the locations are assessed by the verbal variables including very good, good, moderate, poor, very poor, which are scored from one to five. Very good variable for each criterion indicates the best evaluation value per all of the criteria. Locations evaluation values are reported in following tables.

\subsection{Ranking the potential locations}

At this section, verbal variables are converted to quantitative ones then functional weights of the locations are measured using VIKOR and GRA techniques. The functional weights of locations have been shown in following tables by consideration on safety criteria.

\subsubsection{VIKOR ranking results}

At this section, the 40 initial locations are ranked for site layout by distributing and collecting the questionnaire 3 as well as stepwise implementation of VIKOR method. This process is accomplished through following steps:

Step 1: creating the decision matrix: decision matrix is created as indicated in table 7 based on the number of criteria, alternatives and evaluation of all alternatives for different criteria. 
Table 7

Values for evaluation of initial locations for site layout

\begin{tabular}{lrrrrrrrrr}
\hline \multirow{2}{*}{ Alternative-criterion matrix } & \multicolumn{9}{c}{ Relevant criteria } \\
\cline { 2 - 10 } & $C_{1}$ & $C_{2}$ & $C_{3}$ & $C_{4}$ & $C_{5}$ & $C_{6}$ & $C_{7}$ & $C_{8}$ & $C_{9}$ \\
\hline Location (1) & 3.87 & 4.45 & 1.04 & 3.24 & 1.15 & 2.58 & 2.29 & 1.94 & 3.52 \\
Location (2) & 2.04 & 3.50 & 3.39 & 4.43 & 1.17 & 4.10 & 4.37 & 1.47 & 1.00 \\
Location (3) & 4.33 & 2.85 & 2.67 & 1.96 & 3.04 & 3.96 & 3.73 & 4.48 & 2.86 \\
Location (4) & 2.25 & 3.12 & 3.83 & 1.68 & 2.51 & 2.78 & 1.61 & 1.66 & 1.13 \\
Location (5) & 3.60 & 2.77 & 3.43 & 1.12 & 4.02 & 4.07 & 1.89 & 1.85 & 1.97 \\
Location (35) & $\vdots$ & $\vdots$ & $\vdots$ & $\vdots$ & $\vdots$ & $\vdots$ & $\vdots$ & $\vdots$ & $\vdots$ \\
Location (36) & 3.64 & 1.44 & 3.24 & 2.89 & 1.83 & 2.10 & 2.31 & 1.32 & 2.98 \\
Location (37) & 3.53 & 1.29 & 2.14 & 3.46 & 2.35 & 3.14 & 1.48 & 3.84 & 4.31 \\
Location (38) & 3.79 & 1.73 & 3.44 & 1.61 & 1.53 & 2.97 & 3.47 & 1.46 & 4.05 \\
Location (39) & 2.49 & 3.49 & 2.03 & 2.91 & 1.99 & 4.18 & 2.79 & 1.38 & 3.89 \\
Location (40) & 4.05 & 3.75 & 3.89 & 1.24 & 4.08 & 3.69 & 1.30 & 2.77 & 4.43 \\
\hline
\end{tabular}

Step 2: Normalization of the decision matrix: the alternative-criterion decision-making matrix should be normalized. For example, $\mathrm{f}_{\mathrm{ij}}$ is calculated as follows:

$$
\mathrm{f}_{\mathrm{ij}}=\frac{\mathrm{x}_{11}}{\sqrt{\sum_{\mathrm{i}=1}^{40} \mathrm{x}_{1 \mathrm{j}}^{2}}}=\frac{3.87}{\sqrt{3.87^{2}+2.04^{2}+\ldots+4.05^{2}+2.36^{2}}}=0.186
$$

and other $f_{i j}$ values are calculated then the obtained values up to three decimal places are shown as a matrix in Table 8.

Table 8

Normalized matrix of evaluation values of initial locations for site layout

\begin{tabular}{lccccccccc}
\hline \multirow{2}{*}{ Alternative-criterion matrix } & \multicolumn{9}{c}{ Relevant criteria } \\
\cline { 2 - 11 } & $C_{1}$ & $C_{2}$ & $C_{3}$ & $C_{4}$ & $C_{5}$ & $C_{6}$ & $C_{7}$ & $C_{8}$ & $C_{9}$ \\
\hline Location (1) & 0.186 & 0.213 & 0.050 & 0.155 & 0.055 & 0.124 & 0.110 & 0.093 & 0.169 \\
Location (2) & 0.098 & 0.168 & 0.163 & 0.212 & 0.056 & 0.197 & 0.210 & 0.071 & 0.048 \\
Location (3) & 0.208 & 0.137 & 0.128 & 0.094 & 0.146 & 0.190 & 0.179 & 0.215 & 0.137 \\
Location (4) & 0.108 & 0.150 & 0.184 & 0.081 & 0.120 & 0.133 & 0.077 & 0.080 & 0.054 \\
Location (5) & 0.173 & 0.133 & 0.165 & 0.054 & 0.193 & 0.195 & 0.091 & 0.089 & 0.094 \\
& $\vdots$ & $\vdots$ & $\vdots$ & $\vdots$ & $\vdots$ & $\vdots$ & $\vdots$ & $\vdots$ & $\vdots$ \\
Location (35) & 0.175 & 0.069 & 0.155 & 0.139 & 0.088 & 0.101 & 0.111 & 0.063 & 0.143 \\
Location (36) & 0.169 & 0.062 & 0.103 & 0.166 & 0.113 & 0.151 & 0.071 & 0.184 & 0.207 \\
Location (37) & 0.182 & 0.083 & 0.165 & 0.077 & 0.073 & 0.142 & 0.166 & 0.070 & 0.194 \\
Location (38) & 0.119 & 0.167 & 0.097 & 0.140 & 0.095 & 0.200 & 0.134 & 0.066 & 0.187 \\
Location (39) & 0.194 & 0.180 & 0.187 & 0.059 & 0.196 & 0.177 & 0.062 & 0.133 & 0.212 \\
Location (40) & 0.113 & 0.108 & 0.091 & 0.148 & 0.204 & 0.105 & 0.058 & 0.129 & 0.199 \\
\hline
\end{tabular}

Step 3: determining the best and worst value. The best and worst values of each criterion are determined as indicated in Table 9.

\section{Table 9}

The best and worst criteria

\begin{tabular}{crrrrrrrrr}
\hline \multirow{2}{*}{ Relevant features } & \multicolumn{8}{c}{ Relevant criteria } \\
\cline { 2 - 11 } & $C_{1}$ & $C_{2}$ & $C_{3}$ & $C_{4}$ & $C_{5}$ & $C_{6}$ & $C_{7}$ & $C_{8}$ & $C_{9}$ \\
\hline $\mathrm{f}_{i}^{*}$ & 0.213 & 0.048 & 0.050 & 0.215 & 0.211 & 0.216 & 0.214 & 0.215 & 0.212 \\
$\mathrm{f}_{\mathrm{i}}^{-}$ & 0.048 & 0.215 & 0.213 & 0.052 & 0.054 & 0.052 & 0.054 & 0.056 & 0.048 \\
$\mathrm{f}_{\mathrm{i}}^{*}-\mathrm{f}_{\mathrm{i}}^{-}$ & 0.165 & -0.167 & -0.163 & 0.163 & 0.157 & 0.164 & 0.160 & 0.159 & 0.165 \\
\hline
\end{tabular}

Table 10

Maximum and minimum distance between alternatives and the ideal solution

\begin{tabular}{cccc}
\hline $\mathrm{S}^{-}$ & 0.730 & $\mathrm{R}^{-}$ & 0.159 \\
$\mathrm{~S}^{*}$ & 0.266 & $\mathrm{R}^{*}$ & 0.080 \\
$\mathrm{~S}^{-}-\mathrm{S}^{*}$ & 0.463 & $\mathrm{R}^{-}-\mathrm{R}^{*}$ & 0.079 \\
\hline
\end{tabular}


Step 4: calculating the advantage, regret and VIKOR indicators besides determining the potential locations: The considered initial locations are sorted at this step by considering the VIKOR index, where the alternatives with lower $Q_{i}$ have lower preferences. As it is shown, the selected locations 7, 36 and 30 have ranked at the 1 to 3 positions, respectively.

\section{Table 11}

Results of the advantage ( $\mathrm{Si}$ ), regret (Ri) and VIKOR (Qi) indicators and the proposal alternatives ranking

\begin{tabular}{|c|c|c|c|c|}
\hline Alternative & $S_{i}$ & $\mathbf{R}_{\mathbf{i}}$ & $\mathbf{Q}_{\mathbf{i}}$ & Rank \\
\hline Location (1) & 0.562 & 0.157 & 0.807 & 37 \\
\hline Location (2) & 0.534 & 0.114 & 0.502 & 21 \\
\hline Location (3) & 0.348 & 0.105 & 0.247 & 6 \\
\hline Location (4) & 0.709 & 0.117 & 0.710 & 33 \\
\hline Location (5) & 0.524 & 0.140 & 0.659 & 32 \\
\hline & $\vdots$ & $\vdots$ & $\vdots$ & $\vdots$ \\
\hline Location (35) & 0.516 & 0.091 & 0.337 & 10 \\
\hline Location (36) & 0.343 & 0.087 & 0.123 & 2 \\
\hline Location (37) & 0.501 & 0.120 & 0.505 & 23 \\
\hline Location (38) & 0.511 & 0.113 & 0.474 & 19 \\
\hline Location (39) & 0.515 & 0.135 & 0.618 & 31 \\
\hline Location (40) & 0.454 & 0.094 & 0.292 & 7 \\
\hline
\end{tabular}

\subsubsection{Results of GRA ranking}

At this section, the 40 initial locations are ranked for site layout by distributing and collecting the questionnaire 3 as well as stepwise implementation of VIKOR method. This process is done through following steps:

Step 1: forming decision-making matrix: at this step, the opinions collected from the questionnaire and then the criterion-alternative matrix is formed based on the averaged opinions indicated in Table 12.

Table 12

The values of evaluating initial locations for site layout

\begin{tabular}{|c|c|c|c|c|c|c|c|c|c|}
\hline \multirow{2}{*}{ Alternative-criterion matrix } & \multicolumn{9}{|c|}{ Relevant criteria } \\
\hline & $C_{1}$ & $C_{2}$ & $C_{3}$ & $C_{4}$ & $C_{5}$ & $C_{6}$ & $C_{7}$ & $C_{8}$ & $C_{9}$ \\
\hline Location (1) & 3.87 & 4.45 & 1.04 & 3.24 & 1.15 & 2.58 & 2.29 & 1.94 & 3.52 \\
\hline Location (2) & 2.04 & 3.50 & 3.39 & 4.43 & 1.17 & 4.10 & 4.37 & 1.47 & 1.00 \\
\hline Location (3) & 4.33 & 2.85 & 2.67 & 1.96 & 3.04 & 3.96 & 3.73 & 4.48 & 2.86 \\
\hline Location (4) & 2.25 & 3.12 & 3.83 & 1.68 & 2.51 & 2.78 & 1.61 & 1.66 & 1.13 \\
\hline Location (5) & 3.60 & 2.77 & 3.43 & 1.12 & 4.02 & 4.07 & 1.89 & 1.85 & 1.97 \\
\hline$\vdots$ & $\vdots$ & $\vdots$ & $\vdots$ & $\vdots$ & $\vdots$ & $\vdots$ & $\vdots$ & $\vdots$ & $\vdots$ \\
\hline Location (35) & 3.64 & 1.44 & 3.24 & 2.89 & 1.83 & 2.10 & 2.31 & 1.32 & 2.98 \\
\hline Location (36) & 3.53 & 1.29 & 2.14 & 3.46 & 2.35 & 3.14 & 1.48 & 3.84 & 4.31 \\
\hline Location (37) & 3.79 & 1.73 & 3.44 & 1.61 & 1.53 & 2.97 & 3.47 & 1.46 & 4.05 \\
\hline Location (38) & 2.49 & 3.49 & 2.03 & 2.91 & 1.99 & 4.18 & 2.79 & 1.38 & 3.89 \\
\hline Location (39) & 4.05 & 3.75 & 3.89 & 1.24 & 4.08 & 3.69 & 1.30 & 2.77 & 4.43 \\
\hline Location (40) & 2.36 & 2.26 & 1.89 & 3.08 & 4.26 & 2.18 & 1.21 & 2.70 & 4.14 \\
\hline
\end{tabular}

Step 2: forming the normal decision-making matrix: at this step, the matrix is normalized; accordingly, the normal alternative-criterion matrix is indicated in Table 13.

Table 13

Normalized matrix of values evaluating the site layout initial locations

\begin{tabular}{|c|c|c|c|c|c|c|c|c|c|}
\hline \multirow{2}{*}{ Alternative-criterion matrix } & \multicolumn{9}{|c|}{ Relevant criteria } \\
\hline & $C_{1}$ & $C_{2}$ & $C_{3}$ & $C_{4}$ & $C_{5}$ & $C_{6}$ & $C_{7}$ & $C_{8}$ & $C_{9}$ \\
\hline Location (1) & 0.834 & 0.011 & 1.000 & 0.635 & 0.009 & 0.437 & 0.350 & 0.235 & 0.735 \\
\hline Location (2) & 0.300 & 0.284 & 0.309 & 0.985 & 0.015 & 0.883 & 0.973 & 0.093 & 0.000 \\
\hline Location (3) & 0.968 & 0.470 & 0.521 & 0.259 & 0.585 & 0.842 & 0.781 & 1.000 & 0.542 \\
\hline Location (4) & 0.362 & 0.393 & 0.179 & 0.176 & 0.424 & 0.496 & 0.147 & 0.151 & 0.038 \\
\hline Location (5) & 0.755 & 0.493 & 0.297 & 0.012 & 0.884 & 0.874 & 0.231 & 0.208 & 0.283 \\
\hline$\vdots$ & $\vdots$ & $\vdots$ & $\vdots$ & $\vdots$ & $\vdots$ & $\vdots$ & $\vdots$ & $\vdots$ & $\vdots$ \\
\hline Location (35) & 0.767 & 0.874 & 0.353 & 0.532 & 0.216 & 0.296 & 0.356 & 0.048 & 0.577 \\
\hline Location (36) & 0.735 & 0.917 & 0.676 & 0.700 & 0.375 & 0.601 & 0.108 & 0.807 & 0.965 \\
\hline Location (37) & 0.810 & 0.791 & 0.294 & 0.156 & 0.125 & 0.551 & 0.704 & 0.090 & 0.889 \\
\hline Location (38) & 0.431 & 0.287 & 0.709 & 0.538 & 0.265 & 0.906 & 0.500 & 0.066 & 0.843 \\
\hline Location (39) & 0.886 & 0.212 & 0.162 & 0.047 & 0.902 & 0.762 & 0.054 & 0.485 & 1.000 \\
\hline Location (40) & 0.394 & 0.639 & 0.750 & 0.588 & 0.957 & 0.320 & 0.027 & 0.464 & 0.915 \\
\hline
\end{tabular}


Step 3: calculating the gray relational degree matrix: at this step, gray relational degree is calculated for each alternative and the results are indicated in Table 14.

Table 14

Gray relational degree matrix

\begin{tabular}{|c|c|c|c|c|c|c|c|c|c|}
\hline \multirow{2}{*}{ Alternative-criterion matrix } & \multicolumn{9}{|c|}{ Relevant criteria } \\
\hline & $C_{1}$ & $C_{2}$ & $C_{3}$ & $C_{4}$ & $C_{5}$ & $C_{6}$ & $C_{7}$ & $C_{8}$ & $C_{9}$ \\
\hline Location (1) & 0.751 & 0.336 & 1.000 & 0.578 & 0.335 & 0.470 & 0.435 & 0.395 & 0.653 \\
\hline Location (2) & 0.417 & 0.411 & 0.420 & 0.971 & 0.337 & 0.810 & 0.949 & 0.355 & 0.333 \\
\hline Location (3) & 0.940 & 0.485 & 0.511 & 0.403 & 0.547 & 0.759 & 0.696 & 1.000 & 0.522 \\
\hline Location (4) & 0.439 & 0.451 & 0.379 & 0.378 & 0.465 & 0.498 & 0.369 & 0.371 & 0.342 \\
\hline Location (5) & 0.671 & 0.496 & 0.416 & 0.336 & 0.812 & 0.799 & 0.394 & 0.387 & 0.411 \\
\hline 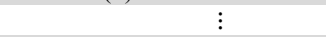 & $\vdots$ & $\vdots$ & $\vdots$ & $\vdots$ & $\vdots$ & $\vdots$ & $\vdots$ & $\vdots$ & $\vdots$ \\
\hline Location (35) & 0.682 & 0.799 & 0.436 & 0.517 & 0.390 & 0.415 & 0.437 & 0.344 & 0.542 \\
\hline Location (36) & 0.653 & 0.857 & 0.607 & 0.625 & 0.444 & 0.556 & 0.359 & 0.722 & 0.935 \\
\hline Location (37) & 0.725 & 0.705 & 0.415 & 0.372 & 0.364 & 0.527 & 0.628 & 0.355 & 0.819 \\
\hline Location (38) & 0.468 & 0.412 & 0.632 & 0.520 & 0.405 & 0.842 & 0.500 & 0.349 & 0.761 \\
\hline Location (39) & 0.815 & 0.388 & 0.374 & 0.344 & 0.837 & 0.678 & 0.346 & 0.493 & 1.000 \\
\hline Location (40) & 0.452 & 0.581 & 0.667 & 0.548 & 0.921 & 0.424 & 0.339 & 0.483 & 0.855 \\
\hline
\end{tabular}

Step 4: calculating the gray relational rank: the gray relational rank of each alternative is calculated at this step. The results are reported in Table 15.

Table 15

Gray relational rank matrix

\begin{tabular}{|c|c|c|c|c|c|c|c|c|c|c|}
\hline Location & 10 & 9 & 8 & 7 & 6 & 5 & 4 & 3 & 2 & 1 \\
\hline$\Gamma$ & 0.664 & 0.738 & 0.555 & 0.686 & 0.570 & 0.541 & 0.419 & 0.645 & 0.577 & 0.528 \\
\hline Rank & 4 & 1 & 20 & 3 & 17 & 24 & 40 & 7 & 13 & 29 \\
\hline Location & 20 & 19 & 18 & 17 & 16 & 15 & 14 & 13 & 12 & 11 \\
\hline$\Gamma$ & 0.573 & 0.489 & 0.537 & 0.648 & 0.527 & 0.491 & 0.534 & 0.602 & 0.484 & 0.588 \\
\hline Rank & 14 & 34 & 25 & 6 & 30 & 33 & 26 & 11 & 35 & 12 \\
\hline Location & 30 & 29 & 28 & 27 & 26 & 25 & 24 & 23 & 22 & 21 \\
\hline$\Gamma$ & 0.623 & 0.698 & 0.453 & 0.562 & 0.563 & 0.494 & 0.475 & 0.662 & 0.631 & 0.499 \\
\hline Rank & 10 & 2 & 38 & 19 & 18 & 32 & 36 & 5 & 9 & 31 \\
\hline Location & 40 & 39 & 38 & 37 & 36 & 35 & 34 & 33 & 32 & 31 \\
\hline$\Gamma$ & 0.570 & 0.572 & 0.532 & 0.548 & 0.638 & 0.530 & 0.463 & 0.554 & 0.550 & 0.426 \\
\hline Rank & 16 & 15 & 27 & 23 & 8 & 28 & 37 & 21 & 22 & 39 \\
\hline
\end{tabular}

According to the gray relational analysis, an alternative with the highest gray relational degree is the preferred alternative; therefore, priority of bank branches is determined based on the gray relational degree. The results obtained from the gray relational degree computations imply that the selected locations 9,29 and 7 are ranked at positions 1 to 3.

\subsection{Sensitivity Analysis of GRA and VIKOR Techniques}

To analyze sensitivity and reliability of the results obtained from the VIKOR method, the effect of various $v$ values on the VIKOR results were examined. The obtained findings are illustrated in the Fig. 1. As it can be seen in this figure, changing alternatives' preferences have minor difference based on the values of the strategy of the majority of group utility $(v)$. Nevertheless, the selected locations 7, 9 , 30 and 36 are the highest ranks.

Therefore, VIKOR technique does not have an acceptable compatibility with changes in $v$ parameter. To examine the effect of different determination coefficients on the results of gray relational analysis, the gray relational degree was calculated for each location by consideration of various determination coefficients. Different determination coefficients were taken in this analysis and the obtained results are shown in Fig. 2. As it is seen, the preferences related to the options have not changed when determination coefficient $(\xi)$ varies and the results obtained from the GRA method are more stable relative to the VIKOR method. 


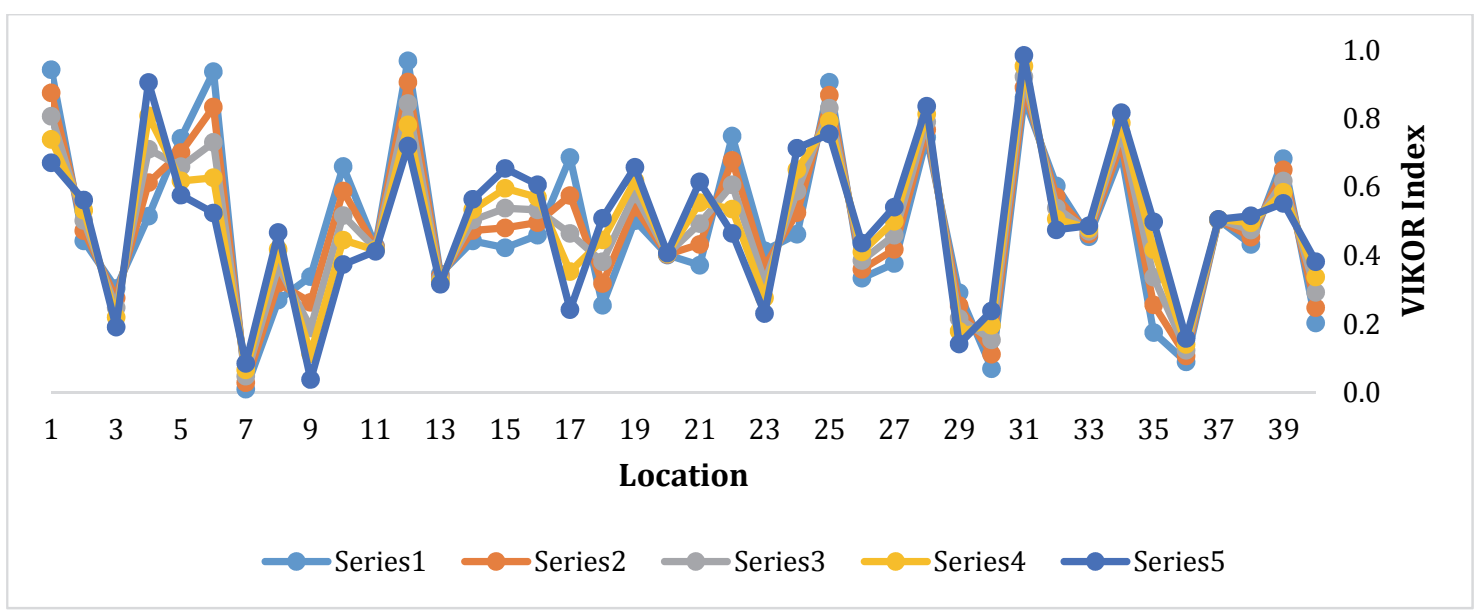

Fig. 2. Sensitivity analysis of VIKOR method

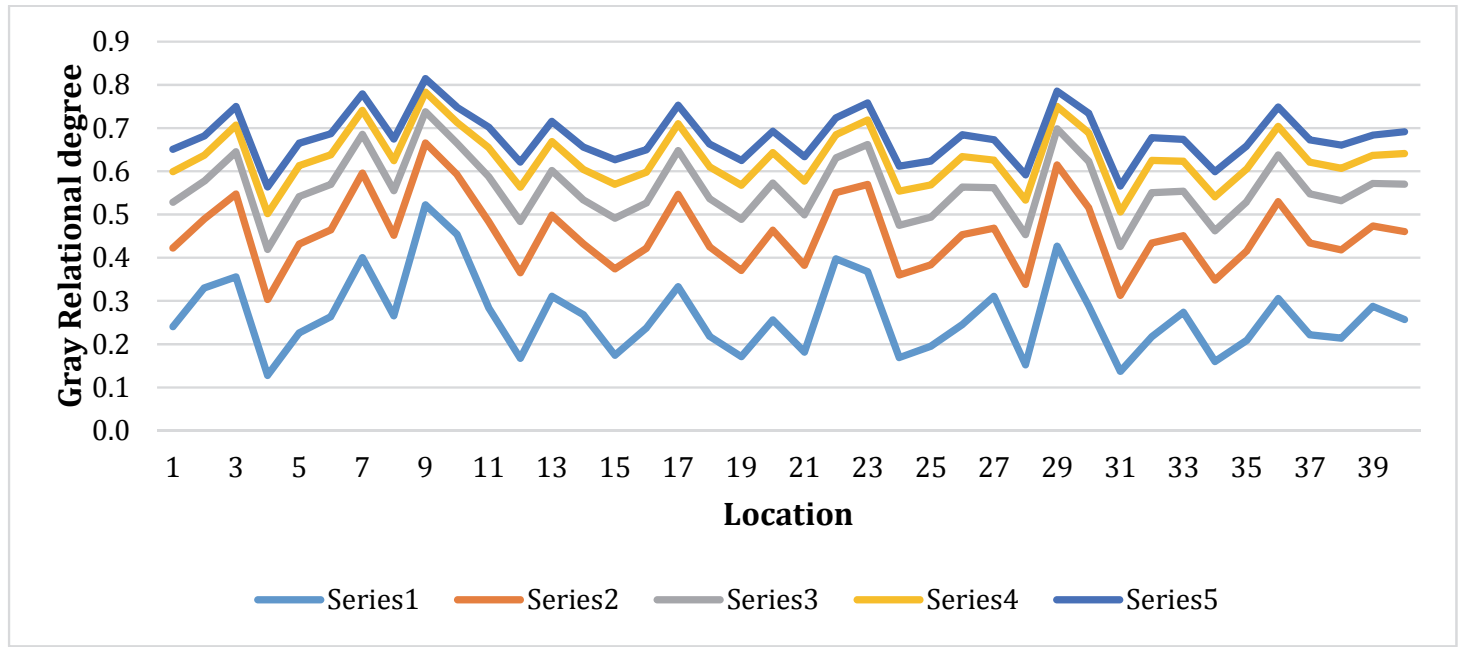

Fig. 3. Sensitivity analysis of GRA method

Ultimately, the potential locations for site layout were determined as indicated in Table 16. It should be noted that the alternatives, which their gray relational degrees were greater than 0.555 were selected as the potential locations based on the consensus of decision makers.

\section{Table 16}

The selected potential locations

\begin{tabular}{lccccc}
\hline Row & Location & $\begin{array}{c}\text { Gray relational } \\
\text { degree }(\boldsymbol{\Gamma})\end{array}$ & Row & Location & $\begin{array}{c}\text { Gray relational } \\
\text { degree }(\boldsymbol{\Gamma})\end{array}$ \\
\hline 1 & Location 9 & 0.738 & 11 & Location 13 & 0.602 \\
2 & Location 29 & 0.698 & 12 & Location 11 & 0.588 \\
3 & Location 7 & 0.686 & 13 & Location 2 & 0.577 \\
4 & Location 10 & 0.664 & 14 & Location 20 & 0.5763 \\
5 & Location 23 & 0.662 & 15 & Location 39 & 0.572 \\
6 & Location 17 & 0.648 & 16 & Location 40 & 0.570 \\
7 & Location 3 & 0.645 & 17 & Location 6 & 0.570 \\
8 & Location 36 & 0.683 & 18 & Location 26 & 0.563 \\
9 & Location 22 & 0.631 & 19 & Location 27 & 0.562 \\
10 & Location 22 & 0.631 & 19 & Location 27 & 0.562 \\
\hline
\end{tabular}

Fig. 3 represents the structure of selected potential locations. 


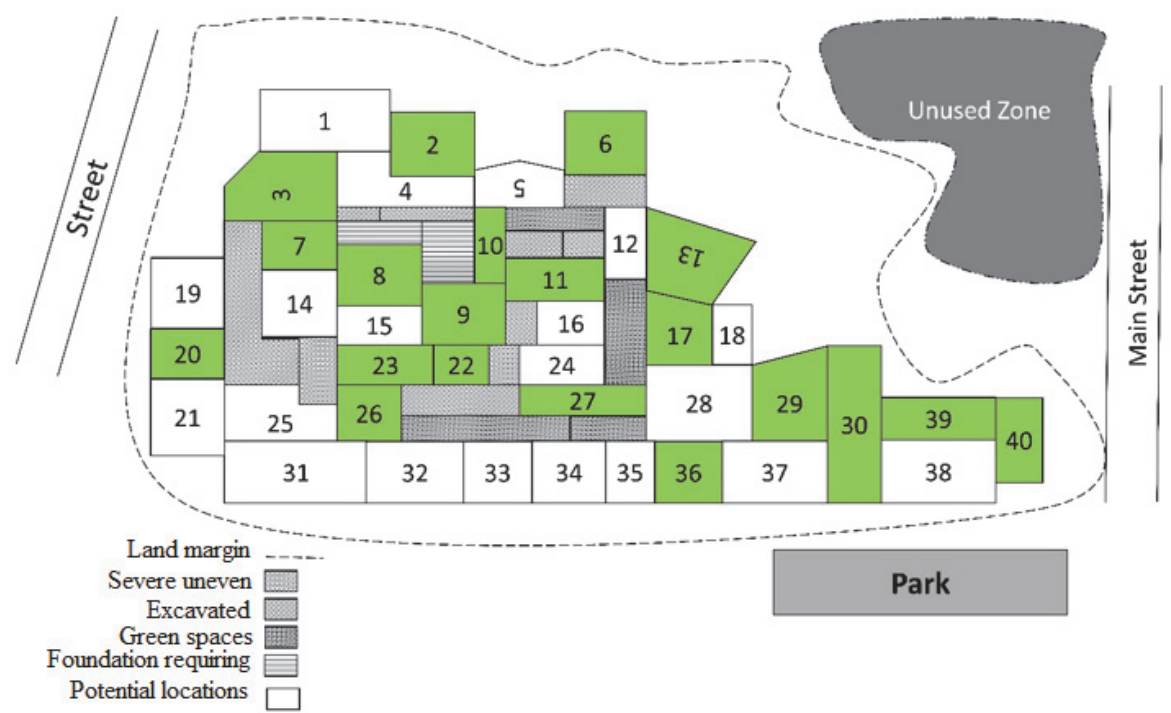

Fig. 3. The selected potential locations for facilities site layout

As it is seen in Fig. 3, almost all of the selected site layout locations are located at the central parts of the site; this may be related to the scores of safety criteria provided by the BWM technique. In fact, the experts believe that safety level at the central part of the site is higher that the marginal space. Moreover, some facilities should be located close to the main street in order to achieve an appropriate transportation system and this can be seen in the obtained results of research.

\section{Conclusion and Further Suggestions}

This study developed a new hybrid method based on the BWM, GRA and VIKOR techniques in order to select the facility location in the construction layout in accordance with the research framework of the construction management area in the Mehr Housing Project in Tehran, Iran. The research executive structure was designed based on the three operational phases. In the first phase, the criteria were extracted from the research literature then approved by the experts. Furthermore, the potential locations were determined for site layout by the experts and the required data were finally collected in the frame of questionnaire for problem solving. At the second phase, the weight of each criterion was determined using BWM. The results obtained from evaluation of potential locations for site facilities layout in this research introduced light shortage, access to standard equipment and flexible safety in equipment as three important criteria. Then, the final ranking of alternatives was done using GRA and VIKOR techniques. Accordingly, three selected alternatives by the GRA were locations 9, 27 and 7; while VIKOR method selected locations 9,36 and 7 as preferred alternatives. The similar ranking of alternatives for the best potential location of construction site layout in these two methods requires application of a method with high reliability. Therefore, sensitivity analysis was done on the parameters existing in VIKOR and GRA methods in the third phase in order to select the best ranking method. The computational results showed higher stability of GRA method compared to the VIKOR method. Accordingly, the GRA ranking can be used as the final response for case study implementation. It is recommended to employ new MCDM methods and compare them in order to evaluate their effectiveness and to develop the research dimensions.

\section{References}

Abune'Meh, M. (2017). Construction Site Layout Optimization, Considering Risk of Natural or Technological Hazard Utilizing GIS. Université Paris-Est. 
Aikhuele, D. (2019). A model for supporting designers and for determining design stakeholders' preferences.International Journal of Data and Network Science, 3(2), 109-118.

Al Hawarneh, A., Bendak, S., \& Ghanim, F. (2019). Dynamic facilities planning model for large scale construction projects. Automation in Construction, 98, 72-89.

Arashpour, M., Wakefield, R., Abbasi, B., Arashpour, M., \& Hosseini, R. (2018). Optimal process integration architectures in off-site construction: Theorizing the use of multi-skilled resources . Architectural Engineering and Design Management, 14(1-2), 46-59 .

Ardeshir, A., Mohseni, N., Behzadian, K., \& Errington, M. (2014). Selection of a bridge construction site using fuzzy analytical hierarchy process in geographic information system. Arabian Journal for Science and Engineering, 39(6), 4405-4420 .

Ataei, E., \& Branch, A. (2013). Application of TOPSIS and fuzzy TOPSIS methods for plant layout design. World Applied Sciences Journal, 24(7), 908-913 .

Banker, R. D., Charnes, A., \& Cooper, W. W. (1984). Some models for estimating technical and scale inefficiencies in data envelopment analysis. Management Science, 30(9), 1078-1092.

Biswas, T \& Saha, P. (2019). Selection of commercially available scooters by new MCDM method. International Journal of Data and Network Science, 3(2), 137-144.

Deng, J.-L. (1982). Control problems of grey systems. Systems \& Control Letters, 1(5), 288-294 .

Durmusoglu, Z. D. (2018). A TOPSIS-based approach for sustainable layout design: activity relation chart evaluation. Kybernetes, 47(10), 2012-2024 .

Esfahani, H. K., \& Nik, M. S. A. (2016). Use of GIS-based Multi-Criteria Decision Making to Optimal Site Selection in an Illustrative Study Area in the Center of Iran. International Journal of Engineering Research, 5(4), 260-263 .

Gupta, H. (2018). Evaluating service quality of airline industry using hybrid best worst method and VIKOR. Journal of Air Transport Management, 68, 35-47 .

Jain, V \& Ajmera, P. (2019). Evaluation of performance factors of FMS by combined decision making methods as AHP, CMBA and ELECTRE methodology.Management Science Letters, 9(4), 519-534.

Jato-Espino, D., Castillo-Lopez, E., Rodriguez-Hernandez, J., \& Canteras-Jordana, J. C. (2014). A review of application of multi-criteria decision making methods in construction. Automation in Construction, 45, 151-162.

Jozi, S. A., Shoshtary, M. T., \& Zadeh, A. R. K. (2015). Environmental risk assessment of dams in construction phase using a multi-criteria decision-making (MCDM) method. Human and Ecological Risk Assessment: An International Journal, 21(1), 1-16 .

Kaveh, A., Rastegar Moghaddam, M., \& Khanzadi, M. (2018). Efficient multi-objective optimization algorithms for construction site layout problem. Scientia Iranica, 25(4), 2051-2062 .

Kumar, A., Sah, B., Singh, A. R., Deng ,Y., He, X., Kumar, P., \& Bansal, R. (2017). A review of multi criteria decision making (MCDM) towards sustainable renewable energy development. Renewable and Sustainable Energy Reviews, 69, 596-609 .

Kumar, S. S., \& Cheng, J. C. (2015). A BIM-based automated site layout planning framework for congested construction sites. Automation in Construction, 59, 24-37 .

Marzouk, M., \& Al Daour, I. (2018). Planning labor evacuation for construction sites using BIM and agent-based simulation. Safety Science, 109, 17 .185-4

Mytilinou, V., Lozano-Minguez, E., \& Kolios, A. (2018). A framework for the selection of optimum offshore wind farm locations for deployment. Energies, 11(7), 1855.

Nguyen, H.-T., Dawal, S. Z. M., Nukman, Y., Rifai, A. P., \& Aoyama, H. (2016). An integrated MCDM model for conveyor equipment evaluation and selection in an FMC based on a fuzzy AHP and fuzzy ARAS in the presence of vagueness. PloS one, 11(4), e0153222 .

Ning, X., Ding, L., Luo, H., \& Qi, S. (2016). A multi-attribute model for construction site layout using intuitionistic fuzzy logic. Automation in Construction, 72, 380-387 .

Önüt, S., Efendigil, T., \& Kara, S. S. (2010). A combined fuzzy MCDM approach for selecting shopping center site: An example from Istanbul, Turkey. Expert systems with applications, 37(3), 1973-1980 . 
Opricovic, S. (1998). Multicriteria optimization of civil engineering systems. Faculty of Civil Engineering, Belgrade, 2(1), 5-21.

Rezaei, J. (2015). Best-worst multi-criteria decision-making method. Omega, 53, 49 .57-

Rezaei, J. (2016). Best-worst multi-criteria decision-making method: Some properties and a linear model. Omega, 64, 126-130 .

Saaty, T. L. (2003). Decision-making with the AHP: Why is the principal eigenvector necessary. European Journal of Operational Research, 145(1), 85-91.

Said, H., \& El-Rayes, K. (2013). Performance of global optimization models for dynamic site layout planning of construction projects. Automation in Construction, 36, 71-78 .

Stanujkić, D., Đorđević, B., \& Đorđević, M. (2013). Comparative analysis of some prominent MCDM methods: A case of ranking Serbian banks. Serbian Journal of Management, 8(2), 213-241 .

Vatansever, K \& Akgül, Y. (2018). Performance evaluation of websites using entropy and grey relational analysis methods: The case of airline companies.Decision Science Letters , 7(2), 119-130.

Yahya, M., \& Saka ,M. (2014). Construction site layout planning using multi-objective artificial bee colony algorithm with Levy flights. Automation in Construction, 38, 14-29 .

Zavadskas, E. K., Antucheviciene, J., Šaparauskas, J., \& Turskis, Z. (2013). Multi-criteria assessment of facades' alternatives: peculiarities of ranking methodology. Procedia Engineering, 57, 107-112 .

Zhang, S.-f., Liu, S.-y., \& Zhai, R.-h. (2011). An extended GRA method for MCDM with intervalvalued triangular fuzzy assessments and unknown weights .Computers \& Industrial Engineering, 61(4), 1336-1341.

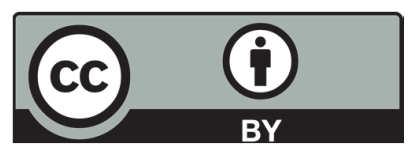

(C) 2019 by the authors; licensee Growing Science, Canada. This is an open access article distributed under the terms and conditions of the Creative Commons Attribution (CC-BY) license (http://creativecommons.org/licenses/by/4.0/). 